\title{
Evaluation of Balance and Fall Risk in Patients with Plantar Fasciitis Syndrome
}

\author{
(D) Mehmet Ağırman \\ Department of Physical Medicine and Rehabilitation, Istanbul Medipol University Faculty of Medicine, Istanbul, Turkey
}

\begin{abstract}
Objectives: In this study, we aimed to investigate plantar fasciitis syndrome on balance and the risks of the falls.

Methods: Fifty patients with clinical diagnosed plantar fasciitis participated in this study. Patients were evaluated using the visual analog scale (VAS) for pain. Balance and fall risk were measured with the biodex balance system. Postural stability and fall risk were measured with total score (TS), antero-posterior (AP) and mediolateral (ML) as statically and dynamically at 2. and 8. degrees. Nineteen healthy volunteers with no active complaints and no previous plantar fasciitis/calcaneal spur were included in this study as a control group.

Results: The mean VAS value in the patient group was $6.65 \pm 1.84$. There was no statistical difference between the mean age and body mass index of patients and control groups. A statistically significant difference was found between the group in TS2 ( $p=0.005$ ), TS8 $(p=0.009), \operatorname{AP} 2(p=0.006), \operatorname{AP} 8(p=0.018), D R 2(p=0.01)$ and DR8 $(p=0.002)$ in favor of the control group. There was no statistical difference between the groups in the static and dynamic mediolateral balance evaluations.

Conclusion: The findings demonstrated that postural balance, especially in the antero-posterior plane, was impaired in patients with plantar fasciitis syndrome and increased risk of falls.

Keywords: Plantar fasciitis; balance; fall risk.

Please cite this article as "Ağırman M. Evaluation of Balance and Fall Risk in Patients with Plantar Fasciitis Syndrome. Med Bull Sisli Etfal Hosp 2019;53(4):426-429".
\end{abstract}

$\mathrm{P}$ lantar fasciitis (PFs) is one of the most common causes of plantar heel pain. ${ }^{[1]} \mathrm{PFs}$ is also named as painful heel syndrome, heel spur syndrome, runner heel, subcalcaneal pain, calcaneodine, plantar fasciosis and calcaneal periostitis. With the presence of triggering factors, repetitive movements, such as walking and running, may result in micro-tears in the plantar fascia. In biopsy samples of affected tissue, degenerative changes in the fascia can be seen with or without fibroblastic proliferation and chronic inflammation. ${ }^{[2]}$

Although PFs is more common in physically active people, such as runners and military personnel, it is especially com- mon in women between the ages of $40-60 \cdot{ }^{[3]}$ Decreased ankle dorsiflexion, increased body mass index and prolonged standing time are among the risk factors. ${ }^{[4]}$

Clinical diagnosis is based on anamnesis and physical examination. Typical pain presents as the pain starts after inactivity, especially in the first steps in the morning or after long-term rest, is alleviated by activity, but towards the end of the day, the pain increased concerning the load on the heel, in the form of deep heel pain. Diagnostic imaging is generally not needed for the initial evaluation and treatment but may be useful for differential diagnosis. Direct ra-

Address for correspondence: Mehmet Ağırman, MD. Istanbul Medipol Universitesi Tip Fakultesi, Fiziksel Tip ve Rehabilitasyon Anabilim Dali, Istanbul, Turkey

Phone: +90 5057000385 E-mail: mehmetagirman@yahoo.com

Submitted Date: March 15, 2018 Accepted Date: May 02, 2018 Available Online Date: November 19, 2019

${ }^{\circ}$ Copyright 2019 by The Medical Bulletin of Sisli Etfal Hospital - Available online at www.sislietfaltip.org

OPEN ACCESS This is an open access article under the CC BY-NC license (http://creativecommons.org/licenses/by-nc/4.0/). 
diographs are useful for differentiating calcaneal stress fractures, calcaneal apophysitis and spondyloarthropathies. Conservative methods are generally sufficient for the treatment. $90-95 \%$ of the patients have a decrease in their complaints within 12-18 months. ${ }^{[4,5]}$

The ability of the body to maintain the center of gravity with minimal oscillations on the support base is called equilibrium. ${ }^{[6]}$ To achieve balance, sensory information must be present; the information must be combined in the brain, and adequate motor response must occur. Sensory information is gathered by visual, auditory and proprioceptive systems. A robust neuromuscular system and adequate muscle strength must be present to obtain an adequate motor response. ${ }^{[7]}$

Loss of balance and fall occur more often in more mobile situations, such as while walking and less frequently in static situations. Therefore, the dynamic evaluation of balance is an important factor. ${ }^{[8]}$

Falling is an important public health problem that causes death and injury in elderly people. Annually, one out of three individuals over 65 years, and half of the individuals over 80 years of age have balance problems resulting in falls. ${ }^{[9]}$

In this study, we aimed to investigate the potential effects of plantar fasciitis, one of the foot problems, which increases the risk of falls in the elderly population, on balance and fall risk in the population younger than 65 years.

\section{Methods}

Patients, who were clinically diagnosed as plantar fasciitis, admitted to the Physical Medicine and Rehabilitation outpatient clinic with heel pain between May 2017 and February 2018, were included in this study. The criteria for clinical diagnosis were localized heel pain in the plantar region for at least one month, increased pain during first walking after waking up or during the walking after resting, and decreased pain at the onset of activity but worsening as the activity continues. In our study, the patients' pain was evaluated using the visual analog scale (VAS). Biodex Balance system was used for the balance and fall risk assessment (Fig. 1). Postural stability (PS) and fall risk (FR) were measured statically and dynamically (at grade 2 and 8). Total score (TS), antero-posterior (AP), mediolateral (ML) and overall stability (OS) indexes for FR were evaluated. Patients with sensory loss at foot or ankle and with a systemic inflammatory disease, such as diabetes mellitus, peripheral neuropathy, rheumatoid arthritis and ankylosing spondylitis, who had undergone corticosteroid injections or physical therapy in the last three months, were excluded from this study. Healthy volunteers (from patients' relatives and hospital staff) of similar age and sex who did not have

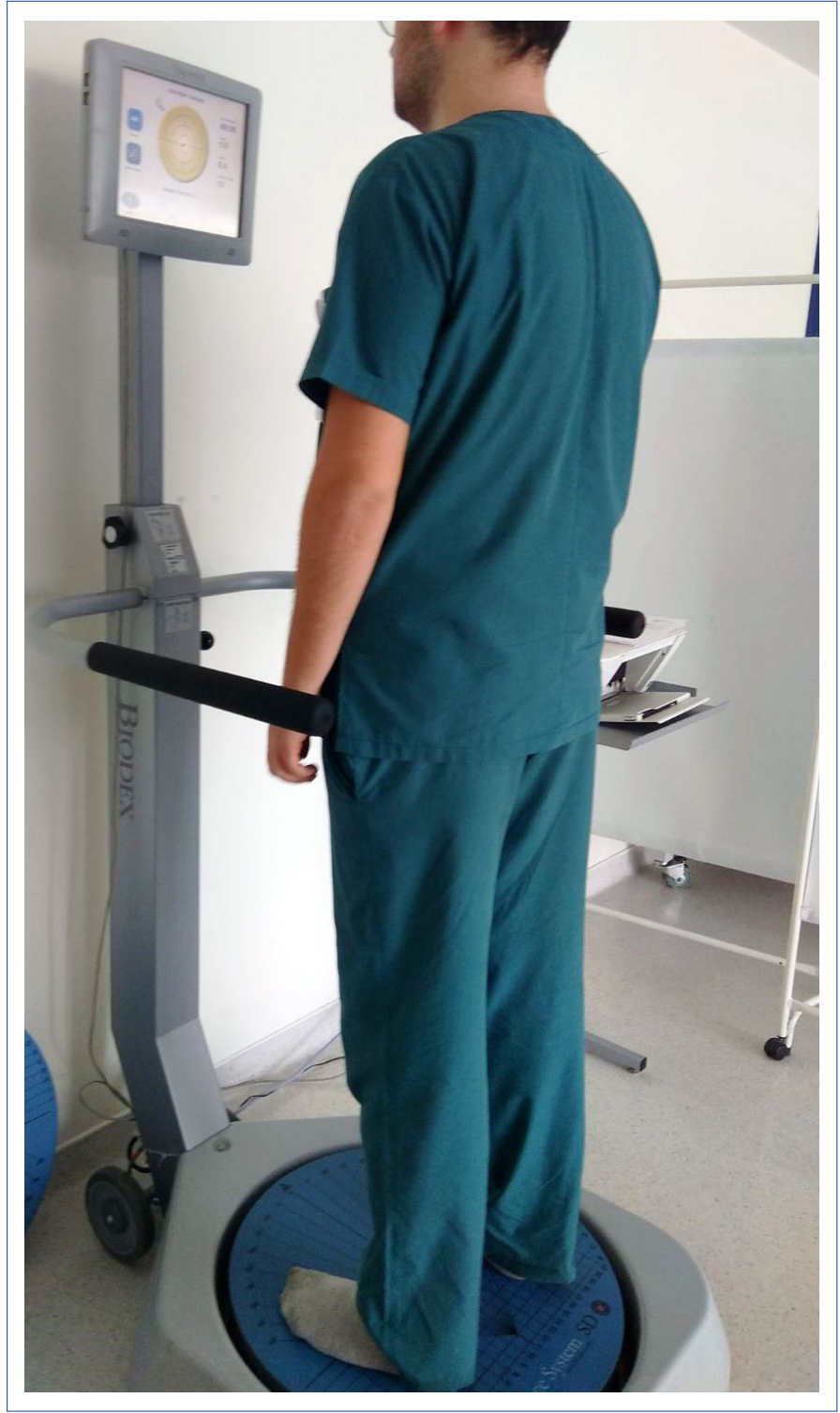

Figure 1. Measurement method with biodex balance system.

active complaints and who had not previously been diagnosed with plantar fasciitis/calcaneal spur were included as the control group in this study. Patients who had a history of illness or signs that might cause balance problems, who used drugs that would cause balance problems, were not included in the study group or healthy volunteers. Local Ethics Committee approval and informed consent about the purpose, duration, and possible problems of this study were taken from the patients included in this study.

\section{Statistical Analysis}

SPSS 17.0 was used for comparison of the data and the number, percentage, average, standard deviation, median and quarters were given for descriptive statistics. Chisquare test was used to compare categorical variables and the Mann-Whitney $U$ test was used to compare the mea- 
surements between the groups. The statistical significance level was accepted as $p<0.05$.

\section{Results}

The mean VAS value in the plantar fasciitis group was $6.65 \pm 1.84$. There was no statistical difference between the mean age and body mass indexes of the patient and control groups $(p>0.05)$. TS2 $(p=0.005)$, TS8 $(p=0.009)$, AP2 $(p=0.006)$, AP8 $(p=0.018), D R 2(p=0.01)$ and DR8 $(p=0.002)$ values were statistically significant in favor of the control group. There was no difference between the groups in the static and dynamic mediolateral balance evaluations (Tables 1, 2).

\section{Discussion}

In this cross-sectional study, it was found that plantar fasciitis, one of the foot problems that increases the risk of falls in the elderly population, also increases the risk of falls in the population younger than 65 years compared to the healthy control group and has a negative effect on balance.

Plantar fasciitis may occur for many different anatomical or biomechanical reasons. The weakness of plantar flexor

Table 1. Demographic data of patient and control groups

\begin{tabular}{lccc}
\hline & Patient (50) & Control (19) & p \\
\hline Age & $41.9 \pm 10.77$ & $44.5 \pm 11.3$ & 0.443 \\
Gender (F/M) & $36 / 14$ & $13 / 6$ & 0.427 \\
BMI & $30.5 \pm 5.1$ & $28.25 \pm 6.55$ & 0.19 \\
VPS & $6.65 \pm 1.84$ & - & - \\
\hline
\end{tabular}

M: Male; K: Female; BMI: Body mass index; VPS: Visual pain scale.

Table 2. Relationship between biodex equilibrium measurements of the patient and control groups

\begin{tabular}{lccc}
\hline & Patient & Control & p \\
\hline PS TS & $0.41 \pm 0.23$ & $0.45 \pm 0.41$ & 0.902 \\
PS AP & $0.25 \pm 0.17$ & $0.27 \pm 0.14$ & 0.287 \\
PS ML & $0.26 \pm 0.23$ & $0.3 \pm 0.38$ & 0.895 \\
PS 8 TS & $1.42 \pm 0.74$ & $1.02 \pm 0.51$ & 0.009 \\
PS 8 AP & $1.07 \pm 0.68$ & $0.74 \pm 0.36$ & 0.018 \\
PS 8 ML & $0.71 \pm 0.38$ & $0.64 \pm 0.33$ & 0.410 \\
PS 2 TS & $2.05 \pm 1.5$ & $1.25 \pm 0.78$ & 0.005 \\
PS 2 AP & $1.46 \pm 1.1$ & $0.86 \pm 0.52$ & 0.006 \\
PS 2 ML & $1.16 \pm 0.97$ & $0.8 \pm 0.5$ & 0.082 \\
DR Static & $0.52 \pm 0.33$ & $0.44 \pm 0.35$ & 0.195 \\
DR 8 & $1.43 \pm 1.1$ & $0.89 \pm 0.3$ & 0.002 \\
DR 2 & $1.73 \pm 1.4$ & $1.06 \pm 0.59$ & 0.010
\end{tabular}

PS: Postural stability test; TS: Total score; FR: Fall risk test; AP: Anteroposterior index; ML: Mediolateral index. muscles (especially finger flexors and abductor hallucis) contributes to PF formation. ${ }^{[10]}$ Kamonseki et al., ${ }^{[11]}$ in one of their studies, showed that strengthening of these muscles in patients with PFs showed to reduce pain and increase dynamic stabilization. According to a prospective study conducted in 176 patients with an average age of 80 , foot plantar flexor muscle weakness and pain increase the risk of falling regardless of etiology. ${ }^{[12]}$ It has been shown that heel eversion and sagittal plan movements increase in these patients; toe plantar flexion increases at the first contact and ground reaction force decreases in the push phase. ${ }^{[13]}$ It has been reported in studies conducted that muscle strength and proprioception are also effective on balance besides falling risk. $^{[7]}$ In our study, the increased risk of falls in patients with plantar fasciitis compared to healthy volunteers indicates that plantar fasciitis also creates a tendency to fall in the young population.

To our knowledge, although there is no study investigating the effects of muscle strength loss on balance in patients with PFs in the literature, various studies showed that quadriceps muscle weakness increases the risk of falling and adversely affects balance in patients with knee osteoarthritis. ${ }^{[14]}$ In a study evaluating 213 patients aged 6080 years, it was found that foot pain due to plantar fasciitis increased the risk of falling more and affected the balance negatively rather than other foot problems (e.g., hallux valgus, pes planus, hammertoe). ${ }^{[15]}$ Similar results in our study support that PFs negatively affects balance, regardless of age. However, the high visual pain score in this study $(6.65 \pm 1.84)$ suggests that it may be a cause of the increased risk of falling. In a meta-analysis performed in elderly people, the findings showed that foot pain had a strong relationship with falls (691 patients; $\mathrm{OR}=2.38$; $95 \%$ confidence interval). ${ }^{[16]}$ However, all studies were conducted in individuals over 60 years of age, and proprioceptive and neuromuscular function losses, which could cause loss of balance and increase the risk of falls, were not evaluated except for pain and foot problems. This suggests that the results of our study arise from plantar fasciitis rather than age-related problems, which strengthens our study.

The limitations of our study include that plantar fasciitis and pain were not evaluated separately and the effects of foot muscle strength-biomechanics on balance and fall risk were not investigated. In further studies, controlled studies can be performed by treating pain and suggesting exercise therapies to increase muscle strength.

\section{Conclusion}

In conclusion, in this study, the findings suggest that the postural balance was disrupted, especially in the antero- 
posterior plane and the risk of falling was increased in young-adult patients with plantar fasciitis syndrome.

\section{Disclosures}

Ethics Committee Approval: The Ethics Committee of İstanbul Medipol University provided the ethics committee approval for this study (17.04.2017/10840098-604.01.01-E.9704).

Peer-review: Externally peer-reviewed.

Conflict of Interest: None declared.

\section{References}

1. Lim AT, How $\mathrm{CH}$, Tan B. Management of plantar fasciitis in the outpatient setting. Singapore Med J 2016;57:168-70. [CrossRef]

2. Roxas M. Plantar fasciitis: diagnosis and therapeutic considerations. Altern Med Rev 2005;10:83-93.

3. Buchbinder R. Plantar fasciitis. N Engl J Med 2004;350:2159-66.

4. Aşansu MA, Yıldırım Y. Topuk Ağrısı. TOTBiD Dergisi 2013;12:44754. [CrossRef]

5. Tsai C-T, Chang W-D, Lee J-P. Effects of short-term treatment with kinesiotaping for plantar fasciitis. J Musculoskelet Pain 2010;18:71-80. [CrossRef]

6. Nichols DS, Glenn TM, Hutchinson KJ. Changes in the mean center of balance during balance testing in young adults. Phys Ther 1995;75:699-706. [CrossRef]

7. Aydoğ E, Yazar D, Bal A, Ekşioğlu E, Ünlü E, Çakçı A. İleri düzeyde varus deformitesi olan bilateral diz osteoartritli hastalarda di- namik postural denge. Arch Rheumatol 2005;20:239-45.

8. Gündüz OH. Yaşlılarda postür ve yürüme. Geriatri 2000;3:155-62.

9. Ambrose AF, Paul G, Hausdorff JM. Risk factors for falls among older adults: a review of the literature. Maturitas 2013;75:51-61.

10. Chang R, Kent-Braun J, Hamill J. Use of MRI for volume estimation of tibialis posterior and plantar intrinsic foot muscles in healthy and chronic plantar fasciitis limbs. Clin Biomech 2012;27:500-5.

11. Kamonseki DH, Gonçalves GA, Yi LC, Júnior IL. Effect of stretching with and without muscle strengthening exercises for the foot and hip in patients with plantar fasciitis: A randomized controlled single-blind clinical trial. Man Ther 2016;23:76-82. [CrossRef]

12. Menz HB, Morris ME, Lord SR. Foot and ankle risk factors for falls in older people: a prospective study. J Gerontol A Biol Sci Med Sci 2006;61:866-70. [CrossRef]

13. Chang R, Rodrigues PA, Van Emmerik RE, Hamill J. Multi-segment foot kinematics and ground reaction forces during gait of individuals with plantar fasciitis. J Biomech 2014;47:2571-7. [CrossRef]

14. Al-Khlaifat L, Herrington LC, Tyson SF, Hammond A, Jones RK. The effectiveness of an exercise programme on dynamic balance in patients with medial knee osteoarthritis: A pilot study. Knee 2016;23:849-56. [CrossRef]

15. Chaiwanichsiri D, Janchai S, Tantisiriwat N. Foot disorders and falls in older persons. Gerontology 2009;55:296-302. [CrossRef]

16. Stubbs B, Binnekade T, Eggermont L, Sepehry AA, Patchay S, Schofield $P$. Pain and the risk for falls in community-dwelling older adults: systematic review and meta-analysis. Arch Phy Med Rehabil 2014;95:175-87. [CrossRef] 